\title{
A comparison of two fixed-term research and development projects that involved collaboration with practices
}

Bill Bytheway, School of Health and Social Welfare, The Open University, Milton Keynes, UK

\begin{abstract}
NHS policies on research and development are aimed at creating a knowledge base for clinical, managerial and policy decisions. This is largely generated through fixedterm projects and through voluntary collaboration between projects and service providers. In this paper, two such projects are compared. They have some basic similarities but also some conspicuous differences. In the analysis, first the planning and launching of the projects are considered, and then their management. Particular attention is paid to the relationship between the scheduling of the projects (and especially their fixed-term funding) and the process of collaboration with primary care practices.
\end{abstract}

Key words: collaboration; fixed-term projects; management; practice development; research; scheduling

\section{Introduction}

NHS policies on research and development are aimed at creating 'a knowledge-based health service in which clinical, managerial and policy decisions are based on sound information about research findings and scientific developments' (Department of Health, 2000: 9). Much of this information is generated through NHS serviceproviding agencies working with fixed-term projects. Policy on health service research management has increasingly promoted close collaboration between research and health service teams. It is argued that this ensures that the work of researchers remains relevant and grounded in current realities and, in turn, that the practices and organization of the health services are directly informed by the fruits of research. Despite this, both in negotiations over collaboration and subsequently in the continuing processes of dissemination, there remains a tension between the scheduling and management of the ongoing work of

Address for correspondence: Bill Bytheway, School of Health and Social Welfare, The Open University, Milton Keynes MK7 6AA, UK. Email: w.r.bytheway@open.ac.uk

(C)Arnold 2000 practitioners in the health service on the one hand, and of fixed-term research projects on the other. The consequences of this for career management are well known. Less frequently discussed are the consequences for project outcomes. This paper will compare two research and development (R \& D) projects, namely Teamcare Valleys (TCV) and the management of long-term medication by older people (LTMOP). They are similar in that each:

- was funded by a government department as part of a wider initiative;

- was of a fixed length;

- was based in a university;

- was undertaken by a multidisciplinary team;

- included both research and development aims;

- was focused on primary health care;

- depended on the voluntary collaboration of general practitioners and other primary health care team members.

However, there are some important differences in terms of length, funds and geographical remit, as well as with regard to aims and the wider context. The basic differences are summarized in Table 1.

The aim of this paper is to compare the ways in which the two projects were planned, launched and 1463-4236(2000)PC033OA 
Table 1 Basic characteristics of the two projects

\begin{tabular}{|c|c|c|}
\hline & Teamcare Valleys (TCV) & $\begin{array}{l}\text { Long-term medication and older people } \\
\text { (LTMOP) }\end{array}$ \\
\hline Funder & Welsh Office & Department of Health \\
\hline Wider initiative & Programme for the valleys & $\begin{array}{l}\text { The Community Health Services Research } \\
\text { Initiative }\end{array}$ \\
\hline Host & University of Wales College of Medicine & $\begin{array}{l}\text { School of Health and Social Welfare, The } \\
\text { Open University }\end{array}$ \\
\hline Fixed term & 3 years & 2 years \\
\hline $\begin{array}{l}\text { Dates } \\
\text { Cost }\end{array}$ & $\begin{array}{l}\text { 1990-1993 } \\
\text { £3000k }\end{array}$ & $\begin{array}{l}1997-1999 \\
\text { £279k }\end{array}$ \\
\hline Research aim & $\begin{array}{l}\text { To undertake a series of projects designed } \\
\text { to raise the quality of practice }\end{array}$ & $\begin{array}{l}\text { To investigate the ways in which older } \\
\text { people routinely acquire, manage and } \\
\text { administer their own medication }\end{array}$ \\
\hline Development aim & $\begin{array}{l}\text { To help to develop primary health care in } \\
\text { the South Wales Valleys }\end{array}$ & $\begin{array}{l}\text { To develop strategies for primary health } \\
\text { care teams to support such patients, and } \\
\text { to prevent the development of iatrogenic } \\
\text { disease }\end{array}$ \\
\hline Wider context & $\begin{array}{l}\text { The economic and social regeneration of a } \\
\text { depressed deindustrialized area }\end{array}$ & $\begin{array}{l}\text { The development of effective community } \\
\text { health services }\end{array}$ \\
\hline Project team & $\begin{array}{l}53 \text { members over the } 5 \text { years, primarily } \\
\text { doctors and nurses, with some social } \\
\text { researchers and support staff }\end{array}$ & $\begin{array}{l}\text { One social researcher, one lecturer } \\
\text { (gerontologist), one part-time senior } \\
\text { lecturer (also part-time GP), seven } \\
\text { fieldworkers, support staff }\end{array}$ \\
\hline Number of practices & 157 & 12 \\
\hline Number of locations & 1 & 4 \\
\hline
\end{tabular}

managed, noting the similarities and differences in the decisions that had to be taken by the project teams with regard to collaboration and the pressures that followed. In conclusion, the resourcing and scheduling of such projects will be discussed and certain issues will be raised regarding the planning of $\mathrm{R} \& \mathrm{D}$ initiatives and the participation of practices. It is beyond the scope of this paper to enter into a detailed discussion of the research methodologies adopted in the two studies. I was employed to work on both projects, so inevitably the two accounts include an autobiographical element.

\section{Planning and launching the projects}

\section{$T C V$}

Teamcare Valleys (TCV) was just one part of a much larger programme aimed at the economic and social regeneration of the South Wales Valleys. With regard to health, the management of the
Welsh NHS was particularly concerned about the high levels of deprivation and long-term illness in the area. Linked to this was a belief that primary health care could address these wider issues and should be developed. It was felt that this could best be achieved through training, improved organization and the promotion of teamwork in the 157 practices in the target area:

The Welsh Office will take a number of new initiatives designed to support the development of primary health care services for Valleys communities. The intention will be to extend vocational training for health professionals working in the Valleys and to provide a more direct role for the University of Wales College of Medicine. Measures to support improved teamwork in the primary care field will also be devised. These initiatives will be discussed with a range of interests, including the relevant Family Practitioner

Primary Health Care Research and Development 2000; 1: 217-228 
Committees, District Health Authorities, professional organizations and the College of Medicine itself. The aim will be to focus on service provision to achieve the best possible effect in the use of primary health care resources for the Valleys.

(Welsh Office, 1988: 31)

These intentions reflect the 'rather nebulous nature' of the early expectations (Bryar and Bytheway, 1996: 11). The Welsh Office took the original initiative, and the basic framework for the project was developed in 1988 and 1989. Little of this detailed planning from before the launch of the project appears to have been documented.

One year after the publication of this programme, a Director was appointed to the project. For several months he undertook a programme of consultations which was partly aimed at securing the active interest of potential collaborating practices. He also set about the process of acquiring premises and appointing staff. This process culminated in over a dozen staff being appointed and commencing work all on the same day in September 1990. They were joined 1 month later by several others (including myself). Our posts had been openly advertised and, although several of the successful applicants knew of the project, I was one of many who came to the project 'cold'. With a few exceptions, we were offered a full-time 3year contract of employment in the College of Medicine. The posts fell into three well-defined categories, namely management, clinical fellows and administrative/secretarial.

The launching strategy document identified five aims. These included sponsoring better health, helping to develop treatment services, providing support, and promoting multidisciplinary teamwork 'through training and other practical measures'. Only one of the aims specifically mentioned research, and then only somewhat incidentally: 'to provide a source of professional, research, management and entrepreneurial expertise to place at the disposal of primary care practitioners in the valleys' (Welsh Office, 1990: 7).

Thus the dominant concern underlying the plans was to change and improve the primary health care services in the valleys. Research, as a distinctive aim, was given a much lower priority than development.

Given the size of the project, the ambition of the aims and the comparatively short duration of our contracts, we appreciated that plans to manage the resources and schedule were urgently needed. Almost immediately we became aware of a complex array of conflicting expectations, both within the newly created team and outside it in the host and funding institutions and the target practices.

In particular, there was uncertainty about the post of 'clinical fellow' (Bryar, 1999). Approximately half of the staff of TCV were appointed to these posts (Bryar and Bytheway, 1996: 213-14). The intention was that they should be experienced primary health care (PHC) practitioners (primarily doctors and nurses), and the expectation was that they would mostly come from practices in the valleys, would work on specific projects in collaboration with one or more practices, and would eventually return to PHC posts in the same area. However, there were conflicting expectations with regard to the nature of the projects they might undertake while at TCV, who would decide what these might be, and in which practices they might be located.

During the preparatory period, many of the practices and health authorities in the target area had come to view the project as a direct investment by the Welsh Office in primary health care services, and many of them were expecting that new funding or extra staff would be made available to them. They were disappointed to see so many people being appointed to posts over which they had no control. We were also conscious of the symbolic importance of the location of our offices - in suburban Cardiff, neither on the College of Medicine campus nor in the valleys. One of the first events that we organized was an official launch, and we noted that few of the intended practice collaborators were present.

It was decided that, within the first few months, all 157 practices should be visited by the clinical fellows, the aim being to explain the aims and objectives of TCV, to find out what needs existed (e.g., for training, research, audit or help in organization) and to identify potential collaborators. This initiative was successful in that it helped to ground the whole project in the target area, and almost immediately a series of individual local projects was launched by the clinical fellows. There was little relationship between these and the various ideas for projects that had emerged from the initial processes of consultation. All of them were 
focused on practice organization and professional practice. Moreover, to a greater or lesser extent all of them were 'housed' within a host practice or practices. As a result, it was possible to conceive of some of the clinical fellows not as 'researchers from an external agency', but as fellow practitioners who had temporarily joined the primary health care team to undertake some 'in-house' practice development. Although several of these projects included a strong element of research methodology, only one of them was referred to a local research ethics committee.

In summary, the main characteristics of this strategy for establishing and launching TCV were as follows:

- a long preparatory period during which potential collaborators were informed of the impending launch of the project;

- a large multidisciplinary project team who began work on the project virtually simultaneously, with little previous acquaintance or knowledge of expectations;

- a large target population of practices, from within which volunteer collaborators were recruited mainly through informal contacts;

- a series of 'in-house' development projects generated by practices, the clinical fellows and health authorities.

Given that TCV was identified with an area of deprivation and poorly developed health services, it was not surprising that many of the potential collaborators viewed the whole project with resentment and suspicion. There was a feeling that it was serving the interests of the College of Medicine rather than the valleys health authorities, and that it was developing the careers of those employed on the project rather than meeting urgent local health needs. The practices and practitioners who decided to collaborate tended to be those who already had some commitment to changing primary health care, and those who recognized that there was some indirect advantage to be gained from collaboration.

\section{LTMOP}

In 1996, the Department of Health (DH) launched the Community Health Services Research Initiative, which identified five priority topic areas. In the School of Health and Social Welfare of the Open University it was decided to bid for funding under this initiative. Various topics were con- sidered, two were submitted and both were successful. One of them, namely LTMOP, focused on the management of medication by older people.

In planning this project, we recognized the potential value of including two distinct aims. One was to contribute to social gerontology, focusing on how routine medication fitted into the everyday lives of older people. The other aim was 'to develop strategies for primary health care teams to support older patients and to prevent the development of iatrogenic disease'.

The latter aim relates specifically to the fourth of the priority topics set by the $\mathrm{DH}$, namely to improve preventive care and to assess the potential of small-scale practical interventions. In this way we created a clear distinction between the research and development aspects of the project. The proposal we submitted broke the project down into 10 scheduled stages with a total of 42 specific tasks.

Given our two aims, it was obvious that the research would require in-depth research methods with a comparatively small number of practices and older people. Nevertheless, we wanted to be able to generalize our findings to prescribing policies and practices in all parts of the UK. We also wanted the subjects (i.e., the patients recruited in each practice) to be representative of the target population at the national level - that is, people aged 75 years and over who had been receiving long-term prescribed medication for more than 12 months and who were living in their own homes. Given these aims, we had to devise a system of recruiting practices which ensured that they were as 'representative' as possible and that, collectively, they represented diversity in locality and practice organization. We decided that our aim in recruiting practices was to obtain a reasonably representative sample of diverse practices.

The fieldwork we planned with the subjects was demanding and time-consuming. The task of explaining the project and recruiting consenting patients was the responsibility of a practice nurse in all eight practices. The patient was asked to give their consent to being interviewed three or four times, to keeping a diary, to showing the interviewer their medicines and how they were stored, and to the research team having access to information abstracted from their medical records. We also wanted there to be sufficient time for each collaborating practice to be fully involved, so that its prescribing procedures could be studied in some

Primary Health Care Research and Development 2000; 1: 217-228 
depth. We appreciated at the outset that we were in rather a dilemma. On the one hand we would be asking a great deal of the practice, and on the other hand we wanted the sample to include practices that were working under pressure and were sceptical about the relevance of research to practice - as well as those that were more likely to engage in this type of collaboration.

We decided to offer payment for the time that a practice would give to the project. By drawing attention to this, we hoped to secure a positive response from practices that might otherwise have refused, and we guessed that they might constitute a sizeable proportion. However, we also accepted that a substantial refusal rate was inevitable. It was important that we took full account of the reasons given for refusal and, where appropriate, sought to persuade the practice to change its decision. We also decided that it would be necessary to weigh the chances of selection in favour or against certain types of practice.

For cost and logistical reasons, we confined the project to four areas and, on pragmatic grounds, we selected four locations in south Wales, north London, Sheffield and the Midlands, each including 50 practices serving 'a range of different kinds of communities'. This generated a sampling frame of over 200 practices.

Over a period of several months, we obtained approval from the four local research ethics committees, and then recruited collaborators by mailing all of these practices, and following up nonresponses with telephone calls. This generated 51 positive expressions of interest. From these we selected four, one in each area, to serve as pilot practices. In order to maximize diversity in the main study, we decided to recruit two contrasting practices from each area. Overall, we felt confident that, by controlling for diversity and maintaining a degree of random sampling, we had achieved our outcome of a 'reasonably representative sample of diverse practices' (see Bytheway et al., 2000: Appendix 1).

In summary, the primary characteristics of the strategy for establishing and launching the LTMOP project were as follows:

- a small project team who had previously worked together, and who had prepared and submitted the proposals which secured funding for the project;
- a long initial period during which we sought ethical approval and an appropriate basis for recruiting a reasonably representative sample;

- a large target population of practices, from within which 'volunteer' collaborators were recruited, mainly by systematic mailing and strategic sampling;

- a tightly scheduled project.

\section{Managing the projects}

\section{$T C V$}

TCV expenditure was determined largely by the steering group (which included the project director and representatives of the Welsh Office, the College and local health authorities). Overall, however, there was no shortage of resources; the main anxiety for the project team related to time and the pressure to deliver successful outcomes. The need for additional staff was occasionally considered by the management team, and the main development here was the appointment of three research officers during the second year of the project.

One aspect of TCV resourcing that changed significantly over the course of the 3 years concerned the Clinical Fellowships (Bryar, 1999). Initially, funds were made available for the appointment of 11 full-time Fellows to extend over the whole 3year period. The intention was that these would be six nurses and five GPs with experience of working in the valleys. They would undertake projects whilst at TCV, drawing upon expertise in the College of Medicine. In this way they would acquire a fund of practical knowledge and expertise which they would take to and implement in practice in the valleys.

At the launch of the project, eight Clinical Fellows were appointed together with two halftime Fellows. This left one nursing post and one GP post vacant. There had been a particularly poor response from doctors, and it was decided to hold these vacancies in reserve. In time it became apparent that some of the ideas coming from the local practices could be accomplished by members of these practice teams being appointed to short-term, part-time Fellowships. This had not been anticipated in the original plans for TCV, but the management team was able to decide on this since it was responsible for making appointments to Fellowships. 
This development produced an extra dimension to TCV. Up to that point, every member of staff was working from the TCV offices in the grounds of Whitchurch Hospital in Cardiff. Certain aspects of this location (such as distance and car parking facilities) acted as a daily disincentive to travelling into the valleys. Although much time was spent in fieldwork away from the offices, through the initial launch and induction we had acquired a strong sense of being members of a team. Much time was spent in our meeting room overcoming important tensions (e.g., between doctors and nurses, and between the management team and the Clinical Fellows). Time was also spent studying in the college library and talking through the idea of what constituted good teamwork.

This sense of group identity was undermined by the appointment of short-term Clinical Fellows. With a few exceptions, these Fellows remained in their practices and rarely, if ever, visited the TCV offices. Their projects were supervised by individual members of the management team and they remained largely isolated from the rest of TCV. Because their projects had short lives and were located wholly in practice, they appeared to be proving cost-effective. In comparison, some of the long-term Clinical Fellows had embarked on substantial projects extending over the whole 3 -year period, and some of them were registered for postgraduate degrees. Increasingly their projects were viewed critically as being too divorced from 'real practice' and not delivering 'outcomes'. Moreover, the short-term Fellows could be interpreted as TCV investing in primary health care teams. Rather than taking people out of practice teams (as had been the case with some of the long-term Fellows), TCV was 'putting money' into practices. The short-term Fellows remained 'full-time' members of the PHC team, despite being formally associated with TCV and the College of Medicine. In this sense, their appointment represented a significant bridging of the apparent gulf between TCV and the target practices. Over the course of the 3-year period, a total of 25 practitioners held a short-term Fellowship.

What is interesting about this development is that although it was largely unplanned, it turned out to be a successful means of overcoming one of the original disappointments, namely the failure of the TCV programme to invest directly in existing PHC teams. Not only was it seen to be a transfer of funds from project to practices, but it was also widely viewed as a successful and effective way of developing practice. Moreover, it helped to alleviate growing problems with regard to scheduling. Initially there had been some confidence that TCV would be extended beyond the 3 years. However, some of the projects of the long-term Clinical Fellows had created tensions with local health authorities, and others appeared to be making slow progress. More generally there was a feeling that TCV was not involving a large enough number of practices. The short-term Clinical Fellow programme seemed to be a timely solution.

However, during the course of the second year, the Welsh Office suddenly became concerned that the project was becoming too diffuse and that it needed a rather tighter system of project management. It strongly advised us to adopt a system known as PRINCE (NHS Management Executive, Leeds; Caan et al., 1997). This involved the identification and specification of all TCV projects, each to be separately planned, resourced, managed and scheduled (within the overall resources and schedule of TCV), and subject to rigorous quality control. Suddenly TCV was transformed from one large project promoting $\mathrm{R} \& \mathrm{D}$ in primary health care on a broad, multidisciplinary and team-based front, to a programme consisting of over 60 small individual projects, each subject to tightly controlled management. PRINCE is designed primarily for organizations with a continuing existence, in which each project needs to be planned individually according to an appropriate schedule. In TCV we were faced with the growing prospect of no continuation beyond the rapidly approaching end of the 3-year period. Nevertheless, considerable time was spent during the second year in implementing PRINCE. However, during the course of the third year, we began to abandon our PRINCE records, and to concentrate once again on working with practices, and in some cases aiding them in obtaining the means to continue projects that TCV had helped to establish. Even in the final months funds were still available, enabling a few further brief short-term Clinical Fellows appointments to be made.

This review demonstrates how the initial fixed term of this project generated a dynamic in the way in which salaried resources were invested and subprojects scheduled. Within the overall fixed term, and subject to pressures and anxieties directly linked to the completion (and possible extension) 
of the fixed term, a changing pattern of devising and implementing new appointments and projects evolved.

\section{LTMOP}

In LTMOP, our collaboration with the eight main study practices followed a more familiar pattern:

- initial visits;

- collaboration in the selection and recruitment of a sample of patients;

- a period of 3 months of fieldwork with patients;

- feedback to practices.

The whole project was based on a tightly scheduled programme structured around the familiar research process of preparation, fieldwork, analysis and dissemination. Collaboration with the eight practices was undertaken concurrently by the project team and seven fieldworkers (Bytheway et al., 2000). Here I shall discuss this collaboration and, in particular, how it varied between practices with regard to resources and scheduling.

Despite obtaining what seemed to be sufficient expressions of interest (as mentioned above, from 51 practices), at the point of drawing a sample and commencing fieldwork (when the pilot study had been completed), one of the selected eight practices dropped out. We attempted to regain the cooperation of this practice, but we soon turned to alternative practices. In succession we approached three others that were similar, from the same area, and had expressed interest. Frustratingly, each decided that they too were no longer interested in collaborating. These exchanges took time, and our tight schedule was now under serious threat.

We decided to approach the practice in the same area that had participated in the pilot study. For this we had interviewed three eligible patients, and we were confident that we would be able to recruit the 10 individuals needed for the main study. The senior partner in this practice readily agreed to collaborate further, but the co-operation of his colleagues in the PHC team was less forthcoming. We were frustrated further by a series of delays and disappointments in the recruitment of patients. In some desperation, I found myself taking drastic steps and, as a 'temporary member' of the practice team, approached patients myself. These measures were beginning to undermine our carefully thought out procedures for ensuring confi- dentiality. Eventually we decided to halt further attempts to recruit patients from this practice, at which point we had obtained a sample of nine and not the intended 10 individuals.

In the mean time, in the other practices another problem was developing. Two practices were being handled by one fieldworker, who had worked out a detailed and tight schedule of interviews with the 20 patients from the two practices. Unfortunately, the practice where she began was small and it, too, was having problems securing the agreement of 10 eligible patients. Again we invested time and effort in this practice, anxious to make the best use of the limited time of the fieldworker. Two of the patients who agreed to participate subsequently dropped out, and although we endeavoured to obtain replacements, this proved impossible. Thus we ended up with a total of only 77 participating patients in the eight practices - three short of the target of 80 .

Concurrent with the fieldwork with patients, we were undertaking a series of visits to the practices in order to obtain details about the organization of their prescribing practices. Again this took time to achieve, given the problems of arranging meetings with busy practitioners in different parts of the country. In total, this phase of the project took about 6 weeks longer to complete than we had planned.

A key element in the process of feeding back our findings to practices and deliberating over their implications consisted of four 'local seminars'. In the original plan these were to follow meetings with the main study practices. Dates had been fixed well in advance, and these served as key markers in sustaining the overall schedule. However, given the problems we had encountered in completing the fieldwork, we did not have sufficient time to meet all the practices before the seminars. We therefore decided to treat the seminars as 'reporting-back' events, at which representatives of the practices could consider and comment on our findings with other key individuals in their areas. We also found that a considerable number of the participating patients had indicated that they would like to be invited to the seminars.

These developments meant that we had to rethink the objectives of the seminars. Rather than discussing findings and the responses of the participating practices with a broad range of local interested parties (including other practices), we 
decided that we should focus on what we had learned from the two practices in the area and what this implied about their effectiveness. We were excited about the prospect of discussions comparing the two practices and involving some of the patients who had participated. Moreover, by deciding to retain the seminar dates, we were in a sense shifting the project back on schedule. By this time we were well into the second half of the project, and regaining a sense of 'being on schedule' was quite a relief.

In many ways the numbers attending the seminars were disappointing. In total, 11 members of the collaborating teams, six other health professionals and nine patients attended. It was evident that many of those who might have come had busy schedules, and taking time out to attend a voluntary meeting was not easy. In some instances the weather deterred individuals from attending. Despite this, all four seminars were successful in that a wide range of issues was covered. All continued well past the scheduled time allowed, and there were many expressions of satisfaction at the end. For example, one GP remarked that he had never before taken part in a meeting with his 'consumers'. He had found the experience most enlightening.

Although the LTMOP project has only recently been completed, and we are currently planning further dissemination, we are able to look back on our collaboration with the eight practices (and the four that took part in the pilot) and draw certain conclusions about practice development.

First, as explained earlier, it was important that we obtained a 'reasonably representative' sample. This was not for reasons of statistical inference, but rather so that a maximum number of other practices could 'identify' with and have confidence in the project. In order for the implications of our findings to be disseminated successfully, and have a real impact on practice, it was critical that members of 'ordinary' PHC teams should be able first to recognize the ordinariness of those with whom we collaborated, and secondly to learn lessons from practices that were reasonably similar to their own.

Secondly, we needed to engage the active collaboration of each practice. What we found was that one member of each practice team took on the task of liaising with us, and another took on the task of drawing and recruiting the sample. It proved more difficult to meet the team as a whole, and particularly to meet those ultimately responsible for prescribing, namely the GPs. Although we had some success here, it proved much more difficult than we had anticipated. For this reason, we consider that we have been less successful in achieving our second aim of developing strategies (see above). To some extent this aim has been transferred into the plan for dissemination.

\section{Results}

With regard to research and development policies in primary health care, the contrast between TCV and LTMOP is revealing. The comparison has shown that, in addition to the similarities listed at the beginning of this paper, the two projects were similar with regard to how the collaboration of practices was sought. Both had a focus on organization and health care practice, and the aim of exploring the potential for improvement. In both cases, practices were free to refuse to collaborate, and careful thought had to be given to gaining the confidence of sceptical doctors, nurses and health authorities.

However, the review has revealed certain critical differences (see Table 2). Notably TCV, unlike LTMOP, was able to begin work on its developmental aim almost immediately. It was keen to work with any practice in the target area. Throughout the 3 years we were periodically anxious about the fact that we were dealing primarily with atypical practices, but the exceptional practice would often be described as demonstrating what was possible rather than what was typical. Another constant concern was the need to increase the number of practices with which TCV collaborated. However, at no point did the recruitment of practices cause any serious delay. All the practices in the target area were in the sampling frame from the beginning.

In contrast, much of the first 8 of the 24 months of LTMOP was devoted to achieving a 'good' sample - to obtaining basic data about practices and populations, securing ethical approval, and then drawing a sample of prospective collaborators. Thus a considerable amount of time was invested in gaining 'representativeness'. We consider that we have had some limited success in achieving this. Given our knowledge both of some of the 
Table 2 Differences between the two projects

\begin{tabular}{|c|c|c|}
\hline & Teamcare Valleys (TCV) & $\begin{array}{l}\text { Long-term medication and older people } \\
\text { (LTMOP) }\end{array}$ \\
\hline Recruiting practices & Instant start & Slow process \\
\hline Identity of collaborators & Complex and, in part, ambiguous & Clear and unambiguous \\
\hline Key unit & The project & The practice \\
\hline Prospects of project continuation & Always possible & Only through further funding \\
\hline Geography & All practices in one area & Selected practices in four areas \\
\hline Tendency & Towards development & Towards research \\
\hline Post-project & Dispersal & Dissemination \\
\hline
\end{tabular}

'battles' we had with potential collaborators (some won and some lost), and of the more idiosyncratic characteristics of the eight practices that were selected, we cannot now claim that they are statistically representative. Rather, we can confidently claim to have worked with 'a representative and diverse sample of eight practices' from four contrasting areas in England and Wales (Bytheway et al., 2000).

Another important difference is that, whereas there is no ambiguity about who was collaborating with LTMOP, TCV undertook many different types of projects, some of which involved a minimum amount of active participation. The imperative was to 'involve' as many PHC practitioners and teams as possible. As a result, considerable efforts were made to draw up membership lists of the 157 ever-changing PHC teams, but this was never satisfactorily completed. Consequently, in the week-to-week monitoring of TCV, 'the project' became the key unit rather than 'the practice' (an aspect of TCV which PRINCE further emphasized). In contrast, the routine management of LTMOP has been based upon the practice.

A third difference arose from the fact that, although TCV was initially only funded for 3 years (1 year more than LTMOP), there was a serious prospect of continuation, and this was an important factor in much of the forward planning of the project team. To a greater or lesser extent we were all committed to the argument that, as a strategy for practice development, TCV 'worked'. Nevertheless, in retrospect it seems likely that the Welsh Office viewed its heavy investment over a comparatively short period of time as no more than 'a short sharp shock' to PHC in the valleys. In con- trast, the funding of LTMOP followed the familiar research model. Some variation in funds between financial years was possible, and as a result there was a 3-month extension. However, continuation in the longer term was always understood to depend on further funding.

Fourthly, the differences in geography and 'demography' are also significant. Whereas at any one time, two dozen or so TCV workers were working with 157 practices, virtually all of them within 50 miles of the project offices, the LTMOP project team of three were collaborating with seven fieldworkers and 12 practices spread across England and Wales. Unlike TCV, LTMOP was unable to act upon serendipitous opportunities for practice development.

Fifthly, perhaps the most interesting difference was the tendency of TCV to drift towards aims of practice development and of LTMOP to drift towards research aims. The commitment of TCV to research was never particularly strong, and the appointment of three researchers was insufficient to redress the balance. Perhaps this was inevitable given the intentions and expectations of the Welsh Office, but the project staff approached their work recognizing both aspects of R \& D work. However, at times it seemed that what was construed as research at TCV was no more than activity that directly supported the aim of development. In contrast, fieldwork for LTMOP was primarily oriented towards research, and development was essentially an elaborated form of dissemination. We agreed contracts with the collaborating practices whereby they were paid to undertake specific tasks, but it proved largely impossible for them to allocate any time to further, less formalized collaboration, as was the case with some practices in the TCV area. 
Finally, not insignificantly, following the termination of TCV the Welsh Office invested in a small continuation project that employed two members of the TCV team. The remaining team members all moved on to other posts that were largely unconnected to the valleys area. There have been a few attempts to document the project and to disseminate the lessons learned. For example, the work involved in the production of an edited book drawing upon 20 of the projects (Bryar and Bytheway, 1996) was essentially unfunded and unconnected with the School of Medicine. A notable exception was funding from the Welsh Office Nursing Division for the production of a report on the nursing aspects of TCV (Bryar, 1993). In contrast, the LTMOP project team all continue to work in the School of Health and Social Welfare of the Open University, and we are actively disseminating the knowledge gained from the project.

\section{Discussion}

Table 3 summarizes the conclusions drawn from this comparative analysis. With regard to scheduling, TCV benefited from its prelaunch preparation. Its problems resulted primarily from the heavy investment being limited to a tight and uncertain schedule (i.e., too large a team for too short a project). Moreover, the uncertainty and abruptness of its ending meant that the wider dissemination of the lessons learned was almost entirely unplanned and left to individual initiative. In contrast, the team of LTMOP was less well prepared when the

Table 3 Comparative strengths and weaknesses

TCV would have benefited from:

- a better balance between staffing and project length;

- a clearer contractual relationship with its collaborators;

- a comparable project in a contrasting area;

- a stronger investment in research, particularly focused on the processes of practice development;

- a stronger commitment by the host institution to dissemination.

LTMOP would have benefited from:

- a longer term, including a 'prelaunch' phase;

- stronger local bases;

- a stronger commitment to practice development. project started, but in the later phases it has not been upset by members of the team searching for alternative employment.

With regard to collaboration, TCV benefited from its narrow geographical boundaries and the closer involvement of local health authorities. LTMOP would have benefited from the appointment of four 'site managers' to work closely with local health authorities in promoting interest and potential collaboration, as well as co-ordinating fieldwork. With regard to wider dissemination, however, it has been unfortunate that TCV was focused on just one particularly deprived area. It has been too easy for those who might learn from TCV to dismiss the valleys as 'atypical' - an area that is rapidly becoming historically anachronistic. Moreover, TCV might have benefited from a clearer contractual relationship between collaborating practice and project, such as characterized LTMOP.

With regard to the balance between research and development, there should have been a clearer research strategy at TCV. All along the priority was on training, development and project management. The research that was undertaken was essentially in-house research - identifying needs and analysing data generated by development projects. The development aim of LTMOP might have been better served by separate funding (and scheduling) for the two basic phases (i.e., fieldwork and dissemination).

Turning to current policies on R\&D in the NHS, projects are now being funded on the basis of fixed-term advance proposals, subject to annual budgetary controls. There are some important weaknesses in this strategy. First, there is no formal recognition of the cost and uncertainties of preliminary work that should be undertaken before a project is launched. This includes consulting interest groups, gaining ethical approval, recruiting NHS provider hosts, setting up collaborative agreements, and so on. When this has to be undertaken at the beginning of a comparatively short fixedterm contract, then it is inevitable that the quality of the research itself will be threatened. Secondly, there is no acknowledgement that variations in the completion of the earlier phases of a project will have major consequences for the completion of the later phases. All too often, preparation and fieldwork take longer than expected and the analysis phase is constricted. As a result, valuable data is 
not examined rigorously and the potential for practice development is not exploited fully. Thirdly, there is no recognition that dissemination is an open-ended activity which, if it is to be completed satisfactorily, might extend over several years. Rather than restrict this important aspect of $R \& D$ either to the fixed term of the project or subsequently to the unpaid initiative of the project workers, the costs might be covered by a one-off completion grant.

Finally, some may conclude from this analysis that it is a mistake to bracket research and development within the framework of single projects, and that it would be preferable for projects to be more clearly one or the other. In my view such a conclusion would be a mistake. Through TCV many project workers became involved in a particularly revealing and productive form of participant observation research. The following two descriptions illustrate something of the extent to which the Clinical Fellowships were important learning experiences for the Fellows involved (incidentally, these two examples also provided LTMOP with important insights into repeat medication and older people):

I sat in the reception area and observed how these (100 requests for repeat prescriptions) were delivered and how they were dealt with. Later I reviewed the notes to determine their quality. I can honestly say that this was one of the most eye-opening experiences of my life. It made me realize that, as GPs, we are protected by our reception staff from raw exposure to the general public. Patients arriving in our consultation rooms have already been 'processed' a little by our staff. The patients' expectations, their ideas, have been affected by their brief encounters with 'the girls on the desk'. As I sat and listened to encounter after encounter, I felt humbled at the realization of how much unscrambling of needs goes on before the door of the GP's room opens. Perhaps this practice was exceptional in degree but, subsequently, similar experience has shown me that it was not unusual in kind.

(Venn, 1996: 95)

Other changes have taken place as a result of the audit. The concerns and expectations of (the Well Elderly Clinic) attenders have changed practice in the following ways: (i) nursing staff always discuss with a clinic attender their medication, hospital tests and referrals, and will refer to the GP if necessary, informing the GP of any proposed action ... (ii) there is an increased awareness of 'people-centredness' within the practice, demonstrated by the protocols (1) on repeat medication (providing a more efficient and effective service for the practice population) ... and (2) on privacy and confidentiality.

(Gill, 1996: 79-80)

In this way TCV produced some valuable qualitative research outcomes. Conversely, there is evidence that participation in LTMOP has contributed to practice development. For example, one GP commented as follows on the report we submitted to the practice:

Since our meeting the partners have all met together to discuss the findings and further meetings are planned. We are intending that some of the written instructions embedded in the repeat prescription should be expanded to give more information about why the treatment is needed, and this is already being implemented.

This illustrates well how feeding back 'research findings' to practices that have provided the entrées that are essential to research and development can have direct consequences for practice.

\section{Acknowledgements}

The work for this paper was undertaken by the author as a Senior Research Fellow of the School of Health and Social Welfare, The Open University. Between 1997 and 1999 the School had received funding from the Department of Health for the LTMOP project. The TCV project was funded by the Welsh Office between 1990 and 1993, and was conducted by the University of Wales College of Medicine. The views expressed in this publication are those of the author and not necessarily those of either the Department of Health or the Welsh Office.

I am grateful to my colleagues, Julia Johnson 
(LTMOP) and Rosamund Bryar (TCV) for valuable comments on this paper.

\section{References}

Bryar, R. 1993: Nursing outcomes of Teamcare Valleys, 19901993. Cardiff: Welsh Office.

Bryar, R. 1999: The transition of practitioner to practitioner researcher in primary health care. $\mathrm{PhD}$ Thesis, University of Wales College of Medicine, Cardiff.

Bryar, R. and Bytheway, B. 1996: Primary health care development. In Bryar, R. and Bytheway, B., editors. Changing primary health care: the Teamcare Valleys experience. Oxford: Blackwell Science, 1-19.

Bytheway, B., Johnson, J., Heller, T. and Muston, R. 2000: The management of long-term medication by older people. Report to the Department of Health. Milton Keynes: School of Health and Social Welfare, The Open University.
Caan, W., Wright, J. and Hampton-Matthew, S. 1997: Start as you mean to go on: project management for beginners. Journal of Mental Health 6: 467-72.

Department of Health 2000: $R \& D$ in primary care. Leeds: NHS Executive.

Gill, J. 1996: Setting standards and developing quality. In Bryar, R. and Bytheway, B., editors. Changing primary health care: the Teamcare Valleys experience. Oxford: Blackwell Science, 74-83.

NHS Management Executive. No date. Using the PRINCE approach in a resource management projects. Leeds: NHS Management Executive.

Venn, C. 1996: Changing prescribing practices. In Bryar, R. and Bytheway, B., editors. Changing primary health care: the Teamcare Valleys experience. Oxford: Blackwell Science, 92-97.

Welsh Office 1988: The Valleys. A programme for the people. Cardiff: Welsh Office.

Welsh Office 1990: Teamcare Valleys strategy. Cardiff: Welsh Office. 